\title{
Higher rate of rheumatic manifestations and delay in diagnosis in Brazilian Fabry disease patients
}

\author{
Nilton Salles Rosa Neto* ${ }^{*}$, Judith Campos de Barros Bento and Rosa Maria Rodrigues Pereira
}

\begin{abstract}
Background: Fabry disease (FD) is an X-linked lysosomal disorder due to mutations in the GLA gene resulting in defective enzyme alpha-galactosidase A. FD patients are frequently misdiagnosed, commonly for rheumatic diseases. Determining pathogenicity of a mutation depends of in silico predictions but mostly on available clinical information and interpretation may change in light of evolving knowledge. Similar signs and symptoms in carriers of GLA gene genetic variants of unknown significance or of benign variants may hamper diagnosis. This study reviews rheumatic and immune-mediated manifestations in a cohort of Brazilian FD patients with classic mutations and also in subjects with GLA gene A143T and R118C mutations. Misdiagnoses, time to correct diagnosis or determination of GLA gene status, time to treatment initiation and reasons for treatment prescription in A143T and R118C subjects are reviewed.

Methods: Genotype confirmed classic FD patients $(n=37)$ and subjects with GLA gene mutations A143T and R118C $(n=19)$ were referred for assessment. Subjects with R118C and A143T mutations had been previously identified during screening procedures at hemodialysis units. All patients were interviewed and examined by a rheumatologist with previous knowledge of disease and/or mutation status. A structured tool developed by the authors was used to cover all aspects of FD and of common rheumatic conditions. All available laboratory and imaging data were reviewed.
\end{abstract}

Results: Thirty-seven consecutive FD patients were interviewed - 16 male / 21 female (mean age: 43.1 years) and 19 consecutive subjects with GLA gene mutations R118C and A143T were evaluated - 8 male / 11 female (mean age: 39.6 years); 15 [R118C] / 4 [A1437]. Misdiagnosis in FD patients occurred in 11 males (68.8\%) and 13 females (61.9\%) of which 10 males and 9 females were previously diagnosed with one or more rheumatic conditions, most frequently rheumatic fever or "rheumatism" (unspecified rheumatic disorder). Median time for diagnosis after symptom onset was 16 years (range, $0-52$ years). Twenty-two patients were treated with enzyme replacement therapy (ERT) - 13 male and 9 female. Median time to ERT initiation after FD diagnosis was 0.5 years (range, 0-15 years). Rheumatic manifestations occurred in $68.4 \%$ of R118C and A143T subjects. Two subjects had been prescribed ERT because of renal disease [R118C] and neuropsychiatric symptoms [A143T].

Conclusion: Misdiagnoses occurred in $64.8 \%$ of FD patients, most frequently for rheumatic conditions. Median time for correct diagnosis was 16 years. Rheumatic manifestations are also frequent in subjects with GLA gene R118C and A143T mutations. These results reinforce the need to raise awareness and increase knowledge about Fabry disease among physicians, notably rheumatologists, who definitely have a role in identifying patients and determining disease burden. Decision to start treatment should consider expert opinion and follow local guidelines.

Keywords: Fabry disease, GLA gene, Misdiagnosis, Diagnostic delay, Rheumatology, Genetic variants of unknown significance

\footnotetext{
* Correspondence: nsalles@yahoo.com

Rheumatology Division, Faculdade de Medicina da Universidade de São,

Paulo, São Paulo, Brazil
}

(c) The Author(s). 2020 Open Access This article is distributed under the terms of the Creative Commons Attribution 4.0 International License (http://creativecommons.org/licenses/by/4.0/), which permits unrestricted use, distribution, and reproduction in any medium, provided you give appropriate credit to the original author(s) and the source, provide a link to the Creative Commons license, and indicate if changes were made. The Creative Commons Public Domain Dedication waiver (http://creativecommons.org/publicdomain/zero/1.0/) applies to the data made available in this article, unless otherwise stated. 


\section{Background}

Fabry disease (FD) is an X-linked lysosomal disorder due to mutations in the GLA gene and where defective enzyme alpha-galactosidase A contributes to accumulation of substrate in numerous organs, with varying degrees of severity and subsequent loss of organ functions. Early diagnosis is the clue to better treatment outcomes $[1,2]$.

FD patients are commonly misdiagnosed [3, 4]. Incorrect diagnoses are often related to rheumatologic conditions, since patients may present with different rheumatic and immune-mediated manifestations [5-13]. Inappropriate diagnosis may lead to improper therapies and delay in FD recognition and adequate treatment initiation, thus hampering prognosis.

Fabry disease in males is characteristically linked to low or absent residual enzyme activity and elevated lyso-Gb3 (globotriaosylsphingosine) - a biomarker of substrate storage. In females, serum levels of residual enzyme activity and of lyso-Gb3 may fall within normal range even in symptomatic probands and thus molecular analysis is required. Diagnosis of Fabry disease requires, therefore, a compatible clinical history with X-linked inheritance associated with altered alpha-galactosidase A assay in male probands, elevated lyso-Gb3 (serum or urinary), and GLA gene analysis depicting a pathogenic mutation. Definition of pathogenicity of a mutation may change in light of evolving knowledge about the pathophysiology of the disease alongside improvement of genetic testing, analysis and interpretation. Whenever possible target-organ tissue portraying storage material should be obtained [14, 15].

Some GLA gene mutations, however, have little interference on enzyme activity and consequently normal or near normal enzyme and lyso-Gb3 levels are found, what is not fully compatible with the pathophysiology of Fabry disease. Hence, it is not reasonable to diagnose probands with such mutations as having Fabry disease.

Nevertheless, the question of pathogenicity remains as in silico analysis might classify some of them as pathogenic and laboratories may disclose results as class I mutations (definitely pathogenic) as recommended by the American College of Clinical Genetics Standards and Guidelines [16].

Probands with questionable mutations are commonly identified in large screening protocols in patients with unspecified kidney failure or cryptogenic cerebrovascular accident or cardiomyopathy. Because of similar signs and symptoms not otherwise explained by another disease, those patients might end up being considered as having Fabry disease. Whenever possible, clinical and pathological data may allow classification as benign mutations. When current available information on a specific mutation is insufficient to determine pathogenicity or benignity, it should be regarded as a genetic variant of unknown significance (GVUS) [14-16].
This is the case with subjects with GLA gene A143T and $\mathrm{R} 118 \mathrm{C}$ mutations. Once considered to be pathogenic, there have been important studies disregarding their roles as disease-causing mutations whereas numerous recent publications relate their presence to evident disease [17-24]. In this sense, carriers of those mutations around the world may receive prescriptions of enzyme replacement therapies or oral chaperone therapy based on degree of symptoms and organ damage. However, it is not clear what other factors might interfere with the presenting phenotype, whether there is a real impact of the GLA gene mutation per se and whether subjects are affected by other undiagnosed disease. Nevertheless, the presence of specific rheumatic manifestations and rheumatological misdiagnosis in subjects with GLA gene A143T and R118C mutations have never been consistently evaluated.

\section{Objectives}

To review rheumatic and immune-mediated manifestations in a cohort of Brazilian FD patients with classic mutations. To review rheumatic and immune-mediated manifestations in subjects with GLA gene A143T and R118C mutations. To review diagnostic errors in those patients, time to correct diagnosis or determination of GLA gene status, and time to treatment initiation when indicated. To review reasons for treatment prescription in A143T and R118C subjects.

\section{Methods}

Genotype confirmed classic FD patients $(n=37)$ and subjects with GLA gene mutations A143T and R118C ( $n=19)$ were referred for assessment. Subjects with R118C and A143T mutations had been previously identified during screening procedures at hemodialysis units. All patients were interviewed and examined by a rheumatologist (NSRN) with previous knowledge of disease and/or mutation status. A structured tool developed by the authors was used to cover all aspects of FD and of common rheumatic conditions. All available laboratory and imaging data was reviewed including lyso-Gb3 analysis. All patients and subjects had had at least one analysis of lyso-Gb3 performed by Centogene, Germany as result of programs of access to diagnosis or treatment follow-up sponsored by the pharmaceutical industry.

Clinical characteristics related to rheumatic or immunemediated signs and symptoms and previous rheumatic diagnosis are described. Attention was given to information about age at first symptoms, age at correct FD diagnosis and age at ERT initiation.

\section{Statistical analysis}

Results are presented as mean and standard deviation for continuous variables and percentages for categorical 
variables. A $p$-value $<0.05$ was required for statistical significance.

\section{Results}

\section{Fabry disease}

Thirty-seven consecutive patients were interviewed - 16 male / 21 female with a mean age of 43.1 years (range, 12-72). Thirty-three were considered to be symptomatic with symptoms associated with FD. All patients had classic mutations which are described in Table 1. Index cases in this cohort were diagnosed because of the following reasons: renal failure - kidney biopsy (Y264SX; L180F); nephrotic syndrome - kidney biopsy (P293S); family screening after screening at hemodialysis unit (R227X; C142R); angiokeratoma (A156D); lymphedema + angiokeratoma + acroparesthesia (W262X); recurrent fever + Fabry crises + acroparesthesia (G271A).

Misdiagnosis occurred in 11 males (68.8\%) and 13 females (61.9\%) of which 10 males and 9 females were previously diagnosed with one or more rheumatologic conditions, most frequently rheumatic fever or "rheumatism" (unspecified rheumatic disorder). Ten of those misdiagnosed patients had angiokeratomas (8 male [72.7\%] and 2 [15.4\%] female) that could aid medical reasoning and bring about Fabry disease as a possible diagnosis. Table 2 summarizes previous rheumatic and non-rheumatic diagnosis.

Median/mean age at first symptoms were 13.0/20.0 years (range, 5-66) overall; 12.0/17.6 years (range, 5-55) for males and 16.5 and 22.1 years (range, 9-66) for females, $p>0.05$. Mean age at diagnosis (including asymptomatic patients) was 35.7 years (range, 4-71) overall; 35.5 years for males (range, 8-55) and 35.9 years for females (range, 4-71) $p>0.05$. Median/mean time for diagnosis after symptom onset was 16.0/18.6 years (range, $0-52$ ) overall; 20.5/21.6 years (range, 1-42) for males; 14.0/17.9 years (range, $0-52$ ) for females, $p>0.05$.

Twenty-two patients were being treated with ERT - 13 male and 9 female and median/mean time to ERT initiation after FD diagnosis was $0.5 / 2.4$ years (range, $0-15$ ) overall; 1.0/3.7 years (range, 0-15) for males; 0/0.4 year (range, 0-1) for females, $\mathrm{p}>0.05$. As for the remaining 3 male patients, two had been recently diagnosed and awaited treatment initiation and the other had started treatment after approximately 6 months of diagnosis but had the delivery of medication interrupted more than 1 year before assessment due to governmental administrative reasons.

Rheumatic manifestations - signs and symptoms were present in 36 patients (97.3\%) which are listed in Table 3. The only patient who did not present any rheumatic symptoms at the time of study was the youngest female at age 12 .

Pain in the extremities (nociceptive and/or neuropathic) was present in 26 patients (70.3\%). This symptom may account not only for classic acroparesthesia but also for arthralgia and myalgia.

Past or present Fabry crises were referred by 16 patients (43.2\%) - all mutations in this cohort had, at least, one male patient with typical Fabry crises. Interestingly, fibromyalgia, a condition characterized by widespread chronic pain, could be diagnosed after thorough rheumatologic assessment in 16 patients (43.2\%). Before FD diagnosis, 2 patients had been misdiagnosed with fibromyalgia.

Bone mineral density abnormalities, which include osteopenia, osteoporosis and low bone mineral density for age, were present in 24 patients (64.8\%). Lymphedema was present in 8 patients $(21.6 \%)$. Only one male

Table 1 List of mutations in this cohort of Fabry disease patients

\begin{tabular}{|c|c|c|c|c|c|c|c|c|}
\hline $\begin{array}{l}\text { \# of } \\
\text { patients }\end{array}$ & Exon & Molecular & Mutation & Type & Description & $\begin{array}{l}\text { ACMG Classification } \\
{[16]}\end{array}$ & $\begin{array}{l}\text { Clinical } \\
\text { Classification }\end{array}$ & Amenability \\
\hline 8 & 3 & c. 424 C > T (p. Cys142Arg) & C142R & missense & $\begin{array}{l}\text { Topaloglu et al. } \\
1999 \text { [25] }\end{array}$ & 1 & Pathogenic & No \\
\hline 8 & 3 & c. 467 C > A (p.Ala156Asp) & A156D & missense & $\begin{array}{l}\text { Turaça et al. } \\
2012 \text { [26] }\end{array}$ & 1 & Pathogenic & No \\
\hline 3 & 3 & c. 540 G > T (p. Leu180Phe) & L180F & missense & $\begin{array}{l}\text { Serebrinsky et al. } \\
2012 \text { [27] }\end{array}$ & 1 & Pathogenic & Yes \\
\hline 2 & 5 & c. 679 C > T (p. Arg227*) & R227X & nonsense & $\begin{array}{l}\text { Davies et al. } \\
1993 \text { [28] }\end{array}$ & 1 & Pathogenic & No \\
\hline 3 & 5 & c. 785 G > A (p. Trp262*) & W262X & nonsense & $\begin{array}{l}\text { Shabbeer et al. } \\
2006 \text { [29] }\end{array}$ & 1 & Pathogenic & No \\
\hline 5 & 6 & c. 812 G > C (p. Gly271Ala) & G271A & missense & $\begin{array}{l}\text { Rosa Neto } \\
2014 \text { [30] }\end{array}$ & 1 & Pathogenic & Yes \\
\hline 1 & 6 & c. 877 C > T (p. Pro293Ser) & P293S & missense & $\begin{array}{l}\text { Cooper et al. } \\
2000[31]\end{array}$ & 1 & Pathogenic & No \\
\hline 7 & 7 & $\begin{array}{l}\text { c. } 1235 \text { 1236delCT (p. } \\
\text { Tyr264Serfs*) }\end{array}$ & Y264SX & deletion & $\begin{array}{l}\text { Blaydon et al. } \\
2001 \text { [32] }\end{array}$ & 1 & Pathogenic & No \\
\hline
\end{tabular}


Table 2 Misdiagnosis in Fabry disease patients

\begin{tabular}{|c|c|c|c|c|c|}
\hline & $\begin{array}{l}\text { Total } \\
\mathrm{N}=37\end{array}$ & $\begin{array}{l}\text { Males } \\
N=16\end{array}$ & $\begin{array}{l}\text { Females } \\
N=21\end{array}$ & Mutations & $p$-value \\
\hline Misdiagnosis - overall, n (\%) & $24(64.8 \%)$ & $11(68.8 \%)$ & $13(61.9 \%)$ & & 0.68 \\
\hline $\begin{array}{l}\text { Patients diagnosed with any rheumatologic condition before } \\
\text { Fabry Disease diagnosis, } n(\%)\end{array}$ & $19(51.4 \%)$ & $10(62.5 \%)$ & $9(42.9 \%)$ & & 0.25 \\
\hline Rheumatic fever, n (\%) & $7(18.9 \%)$ & $4(25 \%)$ & $2(9.5 \%)$ & $\begin{array}{l}\text { A156D } \\
\text { P293S } \\
\text { Y264SX (5) }\end{array}$ & - \\
\hline "Rheumatism" (unspecified rheumatic disorder), n (\%) & $8(21.6 \%)$ & $4(25 \%)$ & $4(19 \%)$ & $\begin{array}{l}\text { A156D (3) } \\
\text { C142R (3) } \\
\text { Y264SX (2) }\end{array}$ & - \\
\hline Rheumatoid arthritis, n (\%) & $1(2.7 \%)$ & 0 & $1(4.8 \%)$ & W262X & - \\
\hline Fibromyalgia, n (\%) & $2(5.4 \%)$ & $1(6.3 \%)$ & $1(4.8 \%)$ & G271A & - \\
\hline Growing pains, n (\%) & $3(8.1 \%)$ & $2(12.5 \%)$ & $1(4.8 \%)$ & $\begin{array}{l}\text { A156D (2) } \\
\text { G271A }\end{array}$ & - \\
\hline Systemic sclerosis, n (\%) & $1(2.7 \%)$ & $1(6.3 \%)$ & 0 & Y264SX & - \\
\hline Tendinopathy, n (\%) & $1(2.7 \%)$ & 0 & $1(4.8 \%)$ & G271A & - \\
\hline Carpal tunnel syndrome, n (\%) & $1(2.7 \%)$ & 0 & $1(4.8 \%)$ & G271A & - \\
\hline $\begin{array}{l}\text { Patients diagnosed with other conditions before Fabry Disease } \\
\text { diagnosis, } n(\%)\end{array}$ & $9(24.3 \%)$ & $3(18.8 \%)$ & $6(28.6 \%)$ & & 0.50 \\
\hline Heart murmur, n (\%) & $1(2.7 \%)$ & $1(6.3 \%)$ & 0 & Y264SX & - \\
\hline Diabetes mellitus, n (\%) & $1(2.7 \%)$ & 0 & $1(4.8 \%)$ & L180F & - \\
\hline Ischemic cardiomyopathy, n (\%) & $1(2.7 \%)$ & 0 & $1(4.8 \%)$ & C142R & - \\
\hline Migraine, n (\%) & $3(8.1 \%)$ & 0 & 3 & $\begin{array}{l}\text { C142R } \\
\text { G271A } \\
\text { W262X }\end{array}$ & 0.13 \\
\hline Fever of unknown origin, n (\%) & $1(2.7 \%)$ & 0 & $1(4.8 \%)$ & A156D & - \\
\hline Focal and segmental glomerulosclerosis, n (\%) & $1(2.7 \%)$ & $1(6.3 \%)$ & 0 & L180F & - \\
\hline Dysmenorrhea, n (\%) & $1(2.7 \%)$ & 0 & $1(4.8 \%)$ & W262X & - \\
\hline Ulcerative colitis, n (\%) & $1(2.7 \%)$ & $1(6.3 \%)$ & 0 & P293S & - \\
\hline
\end{tabular}

Patients may have been misdiagnosed more than once - percentage of the total number of diagnoses is not equal to $100 \%$

Table 3 Rheumatic manifestations in Fabry disease patients

\begin{tabular}{|c|c|c|c|c|}
\hline Signs/Symptoms/Diagnosis & $\begin{array}{l}\text { Total } \\
\text { N (\%) }\end{array}$ & $\begin{array}{l}\text { Males } \\
\mathrm{N}(\%)\end{array}$ & $\begin{array}{l}\text { Females } \\
\mathrm{N}(\%)\end{array}$ & $p$-value \\
\hline Pain in the extremities (nociceptive and/or neuropathic) & $26(70.3 \%)$ & $13(81.3 \%)$ & $13(61.9 \%)$ & 0.21 \\
\hline Fabry crises (past/present) & $15(40.5 \%)$ & $10(62.5 \%)$ & $5(23.8 \%)$ & 0.02 \\
\hline Osteopenia/osteoporosis/ low bone mineral density for age & $24(64.8 \%)$ & $13(81.3 \%)$ & $11(52.4 \%)$ & 0.07 \\
\hline Fibromyalgia & $16(43.2 \%)$ & $6(37.5 \%)$ & $10(47.6 \%)$ & 0.55 \\
\hline Lymphedema & $8(21.6 \%)$ & $7(43.8 \%)$ & $1(4.8 \%)$ & 0.003 \\
\hline Neuropathic osteoarthropathy (Charcot foot) (2 patients = toe amputation) & $4(10.8 \%)$ & $3(18.8 \%)$ & $1(4.8 \%)$ & 0.18 \\
\hline Chronic low back pain & $5(13.5 \%)$ & $1(6.3 \%)$ & $4(19 \%)$ & 0.27 \\
\hline Hip/knee osteoarthritis & $5(13.5 \%)$ & $3(18.8 \%)$ & $2(9.5 \%)$ & 0.43 \\
\hline Gout & $1(2.7 \%)$ & 0 & $1(4.8 \%)$ & - \\
\hline Clinodactyly & $1(2.7 \%)$ & $1(6.3 \%)$ & 0 & - \\
\hline HyperCKemia & $1(2.7 \%)$ & $1(6.3 \%)$ & 0 & - \\
\hline Carpal tunnel syndrome & $3(8.1 \%)$ & 0 & $3(14.3 \%)$ & 0.12 \\
\hline
\end{tabular}

Data in bold means that the difference of frequencies between males and females was statistically significant 
patient presented with bilateral upper and lower limbs lymphedema, and a history of recurrent cellulitis.

Neuropathic osteoarthropathy (Charcot foot) was present in four patients ( 3 male / 1 female). The mutations related were L180F, A156D, C142R, Y264SX. Only one patient had concurrent diabetes mellitus (the female patient), with kidney biopsy, in addition, showing signs of KimmestielWilson lesions and who eventually required toe amputation. All men had been submitted to kidney transplantation and were on immunosuppressive drugs but none had history of glucose imbalance. One male patient required toe amputation and another had been already indicated for toe surgery. Of note, all three patients who required or were indicated for surgery had lymphedema.

Other diagnosis included chronic low back pain in five patients; hip and/or knee osteoarthritis in five patients; gout in one patient; clinodactyly in one patient; unspecific hyperCKemia in one patient; and clinical carpal tunnel syndrome in two patients.

Six immune-related diseases were diagnosed in 4 patients (10.8\%), all female:

a) biopsy-proven and autoantibody positive celiac disease, in a patient with HLA-DQ8 and autoantibody positive hypothyroidism (mutation G271A);

b) autoantibody positive hyperthyroidism (mutation G271A);

c) biopsy-proven IgA nephropathy and psoriasis (mutation L180F);

d) vitiligo (mutation C142R).

Worth mentioning that not all patients underwent autoantibody tests, what might account for underestimation of immune-mediated phenomena.

\section{R118C and A143T subjects}

Nineteen consecutive subjects were evaluated -8 male and 11 female, with a mean age of 39.6 years (range, 9-
66). R118C was detected in 15 patients and A143T in 4. Lyso-Gb3 (Centogene, Germany) levels were normal in all subjects.

Two patients were on Enzyme Replacement Therapy following decision of their treating physician. Application of the Mainz Severity Score Index (MSSI) [33] for FD depicted those 2 patients as "Moderate" severity, which was accounted for:

a) renal (subnephrotic proteinuria/kidney transplantation) [R118C]; and.

b) neuropsychiatric symptoms [A143T].

Thirteen subjects $(68.4 \%)$ presented rheumatic manifestations which are listed in Table 4.

Pain in the extremities in 10 patients (52.6\%); fibromyalgia in 7 patients $(36.8 \%)$. Of note, four patients [3 A143T/ $1 \mathrm{R} 118 \mathrm{C}$ ] referred past/present pain crises comparable to FD.

Osteopenia/osteoporosis in 11 patients (57.9\%);

Other diagnosis included chronic low back pain (3), osteoarthritis (3); trigger finger (1); leg cramps (1).

Interestingly, 4 patients had been previously diagnosed with a rheumatic disease: rheumatoid arthritis (R118C male), rheumatic fever (2 patients - A143T female), and "rheumatism" (A143T female). Three of those patients were affected by pain crises comparable to FD crises. Both patients currently being treated with ERT are included in this group.

\section{Discussion}

The evidence from this study reinforces that Fabry disease is still frequently misdiagnosed. Data from the medical literature have repeatedly shown that many of those patients present unspecific signs and symptoms, but nevertheless require specialized assessment [1, 2]. Our results show that almost $65 \%$ of patients were diagnosed with one or more rheumatological conditions before the correct diagnosis, the higher incidence

Table 4 Rheumatic manifestations in A143T and R118C subjects

\begin{tabular}{|c|c|c|c|c|c|c|c|}
\hline Signs/Symptoms/Diagnosis & $\begin{array}{l}\text { Total } \\
\text { N (\%) }\end{array}$ & $\begin{array}{l}\text { Males } \\
\mathrm{N}(\%)\end{array}$ & $\begin{array}{l}\text { Females } \\
\mathrm{N}(\%)\end{array}$ & $p$-value & $\begin{array}{l}\text { A143T } \\
N(\%)\end{array}$ & $\begin{array}{l}\text { R1 18C } \\
\text { N (\%) }\end{array}$ & $p$-value \\
\hline Pain in the extremities (nociceptive and/or neuropathic) & $10(52.6 \%)$ & $4(50 \%)$ & $6(54.5 \%)$ & 0.86 & $2(50 \%)$ & $8(53.3 \%)$ & 0.34 \\
\hline Fabry-like crises (past/present) & $4(21.1 \%)$ & 0 & $4(36.4 \%)$ & 0.06 & $3(75 \%)$ & $1(6.7 \%)$ & 0.001 \\
\hline Osteopenia/osteoporosis/ low bone mineral density for age & $11(57.9 \%)$ & $5(62.5 \%)$ & $6(54.5 \%)$ & 0.75 & $3(75 \%)$ & $8(53.3 \%)$ & 0.46 \\
\hline Fibromyalgia & $7(36.8 \%)$ & $1(12.5 \%)$ & $6(54.5 \%)$ & 0.07 & $3(75 \%)$ & $4(26.7 \%)$ & 0.08 \\
\hline Chronic low back pain & $3(15.8 \%)$ & $1(12.5 \%)$ & $2(18.2 \%)$ & 0.38 & $2(50 \%)$ & $1(6.7 \%)$ & 0.04 \\
\hline Hip/knee osteoarthritis & $3(15.8 \%)$ & $2(25 \%)$ & $1(9.1 \%)$ & 0.38 & 0 & $3(20 \%)$ & 0.36 \\
\hline Trigger finger & $1(5.3 \%)$ & $1(12.5 \%)$ & 0 & - & 0 & $1(6.7 \%)$ & - \\
\hline Cramps & $1(5.3 \%)$ & $1(12.5 \%)$ & 0 & - & 0 & $1(6.7 \%)$ & - \\
\hline
\end{tabular}

Data in bold means that the difference of frequencies between males and females was statistically significant 
reported in the literature [3, 13, 34]. Gender did not seem to impact in the occurrence of wrong diagnoses.

Furthermore, FD patients also manifest several rheumatic signs and symptoms and may present with immunemediated illnesses irrespective of disease pathophysiology and increase the chances of requiring a pediatric or adult rheumatologist consultation. Median time to FD diagnosis is somewhere between one and two decades after symptoms onset what is similar to what is reported in the literature [2]. In our cohort female patients had a lower median time to diagnosis after symptom onset than males.

Unfortunately, lack of knowledge about the disease from physicians brings about delayed diagnosis and prescription of incorrect treatments [3]. It is important to review classification and diagnostic criteria or clinical characteristics of rheumatic conditions to avoid misdiagnosis. For example, rheumatic fever and growing pains, that are among the most frequent rheumatic misdiagnoses $[3,34]$, have specific features such as age of incidence, family history, pattern of pain, response to medication and usually neuropathic pain is not present $[35,36]$. It is important to say that FD patients do present with arthralgia and myalgia as part of the disease itself, but not true arthritis [11].

Cimaz et al. [37] assessed awareness of rheumatologists about Fabry disease and results highlight that they are not well acquainted with the disease characteristics or with the appropriate workup. In fact, that observation put emphasis on the inclusion of FD and other lysosomal disorders in the differential when investigating multisystemic diseases [38].

Nonetheless, there are rheumatologists who have been interested in finding those rare patients amidst rheumatic patients and investigating specific features such as pain or Raynaud's phenomenon [39-41]. Routine screening of early arthritis, juvenile idiopathic arthritis and fibromyalgia patients have been performed to identify those patients but the yield to definite pathogenic mutations was low [42-44]. Vordenbäumen et al. [45] suggest that regular rheumatology care to early arthritis patients will not overlook patients with FD but reinforce the lack of familiarity of physicians with FD signs and symptoms.

All patients diagnosed with FD in this study had classical mutations and most of them were prescribed ERT. In Brazil, only ERT preparations are approved for use but are not available in the Public Health System and coverage is not expected from insurance companies. Oral chaperone therapy was not available at the time of the study. For the time being, access to ERT depends on judicial request or compassionate use. In this cohort, patients waited a median time of 6 months to start treatment after initial prescription.

In regard to subjects with R118C and A143T GLA gene mutations, identification occurred after screening protocols in dialysis clinics. A143T and R118C subjects were enrolled because they are or were followed by physicians under the label of Fabry disease because of genetic reports confirming pathogenicity of their mutation.

Remarkably, two patients were receiving ERT in arrangement with their attending physician. No histopathological sample was obtained from those patients. All patients had normal levels of Lyso-Gb3 what is in accordance to the literature [15]. However, many of them present signs and symptoms that could be attributed to rheumatic conditions as well as to Fabry disease itself.

When categorized by severity by the MSSI, the patients were classified as "Moderate". Despite the fact that current understanding may not be sufficient to establish a relation between genotype and phenotype, there exist information in the medical literature in support of treatment of some of those patients. It is believed that physicians who choose to treat them do it in the best interest of their patients but constant updates on information regarding pathogenicity should be sought. Noteworthy, those two subjects under ERT had been previously misdiagnosed with a rheumatic disease.

It is important to recognize that some patients with those variants present typical findings of Fabry disease, including angiokeratoma. Our study showed that symptoms that could be defined or described as Fabry-like crises, were present in 4 women, three with A143T and one with R118C. This information may be strongly connected to the occurrence of misdiagnoses with rheumatological conditions.

A lot of controversy exists when those patients are evaluated. It is difficult and expensive to have thorough investigations to include or exclude a diagnosis. It is also difficult and expensive to give such drugs to whom may not need or benefit entirely from them. As stated by Ferreira et al. in the European study [23], R118C variant is frequent in Portugal. Brazil colonization was much influenced by the Portuguese, what may have interfered with the frequency of this variant in our population. It is important to remind that medicine and genetics are constantly evolving disciplines and diagnosis and treatment should be reappraised and readjusted whenever needed.

This paper has several limitations. Despite thorough assessment by a rheumatologist, data is subject to memory bias since not all patients had easy access to health services or regular medical follow-up since childhood. Also, not all patients had autoantibodies assessed, what might underestimate our findings.

\section{Conclusion}

Misdiagnoses occurred in $64.8 \%$ of FD patients, most frequently for rheumatological conditions. Median time for correct diagnosis in this cohort was 16 years. 
Rheumatic manifestations are very frequent in FD, related or not to the pathophysiology of the disease, and some patients may present with concomitant immunemediated diseases.

Rheumatic manifestations are also frequent in subjects with GLA gene R118C and A143T mutations. FD-like pain crises might account for misdiagnosis, and whether the symptoms derive from the gene mutation itself is yet to be determined. In this cohort renal and neuropsychiatric manifestations directed the choice of ERT in 2 of them - one of each mutation. Nonetheless, numerous diseases may present with the same findings. Subjects with questionable mutations warrant further investigation to exclude other diagnosis and, preferably, target biopsy-proven storage accumulation before choosing to initiate FD specific treatment.

Delay in diagnosis in this cohort overall was similar to what is reported in the medical literature with the exception that females had a lower median time to diagnosis than males.

These results reinforce the need to raise awareness and increase knowledge about Fabry disease among physicians, notably rheumatologists, who definitely have a role in identifying patients and determining disease burden. Decision to start treatment should consider expert opinion and follow local guidelines.

\section{Abbreviations}

ERT: Enzyme replacement therapy; F: Female; FD: Fabry disease;

GVUS: Genetic variant of unknown significance; M: Male; MSSI: Mainz severity score index

\section{Acknowledgements}

The authors would like to acknowledge Rachel Sayuri Honjo Kawahira, Jaelson.

Guilhem Gomes, Ana Carolina de Paula and Rosiane Lacerda for referral of. patients.

\section{Authors' contributions}

NSRN designed the study, collected, analyzed and interpreted the data, wrote and reviewed the manuscript. JCBB collected, analyzed and interpreted the data, and reviewed the manuscript. RMRP analyzed and interpreted the data, and reviewed the manuscript. All authors read and approved the final manuscript.

\section{Funding}

FAPE - Brazilian Society of Rheumatology Research Fund.

Brazilian Society of Rheumatology had no role in the design of the study, collection, analysis and interpretation of data and in writing the manuscript.

\section{Availability of data and materials}

The datasets used and/or analyzed during the current study are available from the corresponding author on reasonable request.

\section{Ethics approval and consent to participate}

This work was approved by Faculdade de Medicina da Universidade de São Paulo Ethics Review Board under number 1.464.841 on March 24th 2016. All patients read and signed informed consent. The procedures followed were in accordance with the ethical standards of the responsible committee on human experimentation and with the Helsinki Declaration of 1975, as revised in 1983.
Consent for publication

Not applicable.

\section{Competing interests}

NSRN declares having received speaker's and advisory board fees from Shire HGT, now Takeda Pharmaceuticals; JCBB declares that spouse received speaker's and advisory board fees from Shire HGT, now Takeda

Pharmaceuticals; RMRP has nothing to disclose.

Received: 5 June 2019 Accepted: 26 December 2019

Published online: 06 January 2020

\section{References}

1. Schiffmann R. Fabry disease. Handb Clin Neurol. 2015;132:231-48.

2. Germain DP. Fabry disease. Orphanet J Rare Dis. 2010;5:30.

3. Marchesoni $C L$, Roa N, Pardal AM, Neumann P, Cáceres G, Martínez P, et al. Misdiagnosis in Fabry disease. J Pediatr. 2010;156(5):828-31.

4. Lidove O, Kaminsky P, Hachulla E, Leguy-Seguin V, Lavigne C, Marie I, et al. FIMeD investigators. Fabry disease 'The new great Imposter': results of the French Observatoire in Internal Medicine Departments (FIMeD). Clin Genet. 2012;81(6):571-7.

5. Paira SO, Roverano S, Iribas $\mathrm{J}$, Barceló HA. Joint manifestations of Fabry's disease. Clin Rheumatol. 1992;11(4):562-5.

6. Michels $\mathrm{H}$, Mengel E. Lysosomal storage diseases as differential diagnoses to rheumatic disorders. Curr Opin Rheumatol. 2008;20(1):76-81.

7. Manger B, Menge E, Schaefer R, Haase C, Seidel J, Michels H. Gaucher disease, Fabry disease and mucopolysaccharidosis type I--how can the rheumatologist recognize these patients? Z Rheumatol. 2006;65(1):32 34-43.

8. Manger B, Mengel E, Schaefer RM. Rheumatologic aspects of lysosomal storage diseases. Clin Rheumatol. 2007;26(3):335-41.

9. James RA, Singh-Grewal D, Lee SJ, McGill J, Adib N. Australian Paediatric rheumatology group. Lysosomal storage disorders: a review of the musculoskeletal features. J Paediatr Child Health. 2016;52(3):262-71.

10. Lidove O, Zeller V, Chicheportiche V, Meyssonnier V, Sené T, Godot S, et al. Musculoskeletal manifestations of Fabry disease: a retrospective study. Joint Bone Spine. 2016;83(4):421-6.

11. Politei J, Remondino G, Heguilen R, Wallace E, Durand C, Schenone A. When arthralgia is not arthritis. Eur J Rheumatol. 2016;3(4):182-4.

12. Pagnini I, Borsini W, Cecchi F, Sgalambro A, Olivotto I, Frullini A, et al. Distal extremity pain as a presenting feature of Fabry's disease. Arthritis Care Res (Hoboken). 2011;63(3):390-5.

13. Moiseev S, Karovaikina E, Novikov PI, Ismailova D, Moiseev A, Bulanov N. What rheumatologist should know about Fabry disease. Ann Rheum Dis. 2019. https://doi.org/10.1136/annrheumdis-2019-215476 [Epub ahead of print]

14. Van der Tol L, Smid BE, Poorthuis BJ, Biegstraaten M, Deprez RH, Linthorst $G E$, et al. A systematic review on screening for Fabry disease: prevalence of individuals with genetic variants of unknown significance. J Med Genet. 2014;51(1):1-9.

15. Duro G, Zizzo C, Cammarata G, Burlina A, Burlina A, Polo G, et al. Mutations in the GLA Gene and LysoGb3: Is It Really Anderson-Fabry Disease? Int J Mol Sci. 2018;19(12):E3726. https://doi.org/10.3390/ijms19123726.

16. Richards S, Aziz N, Bale S, Bick D, Das S, Gastier-Foster J, et al. Standards and guidelines for the interpretation of sequence variants: a joint consensus recommendation of the American College of Medical Genetics and Genomics and the Association for Molecular Pathology. Genet Med. 2015; 17(5):405-24.

17. Hauth L, Kerstens J, Yperzeele L, Eyskens F, Parizel PM, Willekens B. Galactosidase Alpha p.A143T Variant Fabry Disease May Result in a Phenotype With Multifocal Microvascular Cerebral Involvement at a Young Age. Front Neurol. 2018;9:336.

18. Lenders M, Weidemann F, Kurschat C, Canaan-Kühl S, Duning T, Stypmann J, et al. Alpha-Galactosidase A p.A143T, a non-Fabry disease-causing variant. Orphanet J Rare Dis. 2016;11(1):54.

19. Corry A, Feighery C, Alderdice D, Stewart F, Walsh M, Dolan OM. A family with Fabry disease diagnosed by a single angiokeratoma. Dermatol Online J. $2011 ; 17(4): 5$

20. De Brabander I, Yperzeele L, Ceuterick-De Groote C, Brouns R, Baker R, Belachew $\mathrm{S}$, et al. Phenotypical characterization of a-galactosidase a gene mutations identified in a large Fabry disease screening program in stroke in the young. Clin Neurol Neurosurg. 2013;115(7):1088-93. 
21. Smid BE, Hollak CE, Poorthuis BJ, van den Bergh Weerman MA, Florquin $\mathrm{S}$, Kok WE, et al. Diagnostic dilemmas in Fabry disease: a case series study on GLA mutations of unknown clinical significance. Clin Genet. 2015;88(2):161-6.

22. Talbot A, Nicholls K. Elevated Lyso-Gb3 suggests the R118C GLA mutation is a pathological Fabry variant. JIMD Rep. 2019;45:95-8.

23. Ferreira S, Ortiz A, Germain DP, Viana-Baptista M, Caldeira-Gomes A, Camprecios $\mathrm{M}$, et al. The alpha-galactosidase a p.Arg118Cys variant does not cause a Fabry disease phenotype: data from individual patients and family studies. Mol Genet Metab. 2015;114(2):248-58.

24. Caetano F, Botelho A, Mota P, Silva J, Leitão MA. Fabry disease presenting as apical left ventricular hypertrophy in a patient carrying the missense mutation R118C. Rev Port Cardiol. 2014;33(3):183.e1-5.

25. Topaloglu AK, Ashley GA, Tong B, Shabbeer J, Astrin KH, Eng CM, et al. Twenty novel mutations in the alpha-galactosidase a gene causing Fabry disease. Mol Med. 1999;5(12):806-11.

26. Turaça LT, Pessoa JG, Motta FL, Muñoz Rojas MV, Müller KB, Lourenço CM, et al. New mutations in the GLA gene in Brazilian families with Fabry disease. J Hum Genet. 2012;57(6):347-51.

27. Serebrinsky GP, Migueles R, Politei JM. Personal communication of mutation L180F. Available at www.fabry-database.org/mutants. Accessed 13 Feb 2019.

28. Davies JP, Winchester BG, Malcolm S. Mutation analysis in patients with the typical form of Anderson-Fabry disease. Hum Mol Genet. 1993;2(7):1051-3.

29. Shabbeer J, Yasuda M, Benson SD, Desnick RJ. Fabry disease: identification of 50 novel alpha-galactosidase a mutations causing the classic phenotype and three-dimensional structural analysis of 29 missense mutations. Hum Genomics. 2006:2(5):297-309.

30. Rosa Neto NS. Identification and clinical characterization of a novel alphaGalactosidase a mutation. J Inborn Errors Metab Screen. 2014;2. https://doi. org/10.1177/2326409814554700.

31. Cooper A, Cooper JA, Wraith JE. Human gene mutations in GLA. Hum Genet. 2000;107:535-6.

32. Blaydon D, Hill J, Winchester B. Fabry disease: 20 novel GLA mutations in 35 families. Hum Mutat. 2001;18(5):459.

33. Whybra C, Kampmann C, Krummenauer F, Ries M, Mengel E, Miebach E, et al. The Mainz severity score index: a new instrument for quantifying the Anderson-Fabry disease phenotype, and the response of patients to enzyme replacement therapy. Clin Genet. 2004;65(4):299-307.

34. Mehta A, Ricci R, Widmer U, Dehout F, Garcia de Lorenzo A, Kampmann C, et al. Fabry disease defined: baseline clinical manifestations of 366 patients in the Fabry outcome survey. Eur J Clin Investig. 2004;34(3):236-42.

35. Carapetis JR, Beaton A, Cunningham MW, Guilherme L, Karthikeyan G, Mayosi BM, et al. Acute rheumatic fever and rheumatic heart disease. Nat Rev Dis Primers. 2016;2:15084

36. Lehman PJ, Carl RL. Growing pains. Sports Health. 2017;9(2):132-8.

37. Cimaz R, Guillaume S, Hilz MJ, Horneff G, Manger B, Thorne JC, et al. Awareness of Fabry disease among rheumatologists - current status and perspectives. Clin Rheumatol. 2011;30(4):467-75.

38. Cimaz R. Lysosomal storage diseases: underrecognized by rheumatologists? Ann Rheum Dis. 2010;69(suppl 3):27.

39. Lidove O, Noel E, Hachulla E, Gaches F, Douillard C, Darne B, et al. Characteristics of Pain in Fabry Disease. (abstract \#256). Presented at the 2014 American College of Rheumatology/Association of Rheumatology Health Professionals Annual Meeting, November 14-19, in Boston, Massachusetts.

40. Kaminsky P, Barbey F, Jaussaud R, Gaches F, Leguy-Seguin V, Hachulla E et al. Pain As Predictor of Organ Involvement in Fabry Disease. (abstract \#255). Presented at the 2014 American College of Rheumatology/ Association of Rheumatology Health Professionals Annual Meeting, November 14-19, in Boston, Massachusetts.

41. Deshayes S, Jaussaud R, Imbert B, Lidove O, Parienti JJ, Triclin N et al. Prevalence of Raynaud's Phenomenon and Nailfold Capillaroscopic Abnormalities in Fabry's Disease: A Cross-Sectional Study. (abstract \#2193) Presented at the 2014 American College of Rheumatology/Association of Rheumatology Health Professionals Annual Meeting, November 14-19, in Boston, Massachusetts.

42. Vordenbäumen S, Brinks R, Richter JG, Albrecht K, Schneider M. Clinical characteristics of patients with alpha-galactosidase a gene variants in a German multicenter cohort of early undifferentiated arthritis. Ann Rheum Dis. 2019. https://doi.org/10.1136/annrheumdis-2019-215223 [Epub ahead of print].
43. Gonçalves MJ, Mourão AF, Martinho A, Simões O, Melo-Gomes J, Salgado M, et al. Genetic Screening of Mutations Associated with Fabry Disease in a Nationwide Cohort of Juvenile Idiopathic Arthritis Patients. Front Med (Lausanne). 2017:4:12.

44. Hasunuma T, Araki N, Nakamura K, Shikano K, Momosaki K, Kawai S, et al. Significance Of Measuring Alpha-Galactosidase A In Fibromyalgia Patients: Possibility Of Fabry disease In Fibromyalgia Patients. Ann Rheum Dis. 2015; 74(suppl 2):1217.

45. Vordenbäumen S, Brinks R, Richter JG, Albrecht K, Schneider M. Response to 'what rheumatologist should know about Fabry disease' by Moiseev et al. Ann Rheum Dis. 2019. https://doi.org/10.1136/annrheumdis-2019-215516 [Epub ahead of print].

\section{Publisher's Note}

Springer Nature remains neutral with regard to jurisdictional claims in published maps and institutional affiliations.
Ready to submit your research? Choose BMC and benefit from:

- fast, convenient online submission

- thorough peer review by experienced researchers in your field

- rapid publication on acceptance

- support for research data, including large and complex data types

- gold Open Access which fosters wider collaboration and increased citations

- maximum visibility for your research: over $100 \mathrm{M}$ website views per year

At $\mathrm{BMC}$, research is always in progress.

Learn more biomedcentral.com/submissions 